\title{
Proceeding
}

Supplementary Issue: Spring Conferences of Sports Science. Costa Blanca Sports Science Events, 14-15 June 2019. Alicante, Spain.

\section{Description of injuries and associated factors of Colombians athletes with physical and sensory - visual disabilities}

\author{
JAVIER EDUARDO MOSQUERA MANRIQUE ${ }^{1,2,3}$, MOISES ARTURO CABRERA HERNANDEZ1', \\ ADRIANA HERNANDEZ MANTILLA ${ }^{4}$, JIMENA ALEXANDRA SIERRA CABRERA ${ }^{5}$, SERGIO ANDRÉS \\ GARCÍA-CORZO1 1 , GUSTAVO ADOLFO CASTRO VARGAS², LUIS JAVIER TAFUR TASCÓN", \\ CARMEN XIMENA TEJADA ROJAS ${ }^{1}$ \\ ${ }^{1}$ Area of Medicine and Special Test (MEDES), Faculty of Education and Sport Sciences, University Institution \\ National Sports School, Cali, Colombia \\ 2Faculty of Medicine, University El Bosque, Bogotá, Colombia \\ ${ }^{3}$ Cali Sports Association, Cali, Colombia \\ ${ }^{4}$ Administrative Department of Sports, Recreation, Physical Activity and the Use of Free Time, \\ COLDEPORTES, Colombia \\ 5 Juan N Corpas University Foundation, Bogotá, Colombia
}

\begin{abstract}
Purpose: Describe injuries and factors that affect athletes with physical, and sensory-visual disabilities of the Bogotá team. Methods: 165 data from medical records of athletes with disabilities of Paralympic movement

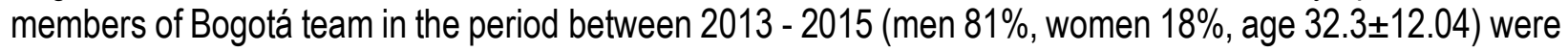
chosen for this study. Results: The prevalence of injuries found in the Bogotá selection was $60 \%$ with a proportional incidence of 2.09 injuries / athlete. The most common lesion location was the upper extremities $(46 \%)$. The most injured anatomical structure was muscle (31\%). Athletics are the sport with higher prevalence of injuries. Of the 345 injuries, $90 \%$ were presented in the training of the athletes, with the gradual onset of the lesion being greater (56.5\%). Main cause of the injuries are due to overuse mechanism $(68.4 \%)$. Conclusions: Investigations like these, are the basis for very specific prevention programs for Paralympic athletes. Keywords: Injuries; Colombia; Disability; Athletes.

Cite this article as:

Mosquera, J.E., Cabrera, M.A., Hernandez, A., Sierra, J.A., Garcia-Corzo, S.A., Castro, G.A., Tafur, L.J., \& Tejada, C.X. (2019). Description of injuries and associated factors of Colombians athletes with physical and sensory - visual disabilities. Journal of Human Sport and Exercise, 14(4proc), S1149-S1162. doi:https://doi.org/10.14198/ihse.2019.14.Proc4.80

Corresponding author. Area of Medicine and Special Test (MEDES), Faculty of Education and Sport Sciences, Institución Universitaria Escuela Nacional del Deporte, Cali, Valle del Cauca, Colombia.

E-mail: sergio.garcia@endeporte.edu.co

Supplementary Issue: Spring Conferences of Sports Science. Costa Blanca Sports Science Events, 14-15 June 2019. Alicante, Spain.

JOURNAL OF HUMAN SPORT \& EXERCISE ISSN 1988-5202

(c) Faculty of Education. University of Alicante

doi:10.14198/jhse.2019.14.Proc4.80
\end{abstract}

VOLUME 14 | Proc4 | 2019 | $\mathbf{S 1 1 4 9}$ 


\section{INTRODUCTION}

Paralympic sports had its beginnings in 1948 in the so-called Stoke Mandeville Games, thanks to Sir Ludwig Guttman, considered the father of the Paralympic Games (Bailey, 2008). Since then, it has shown rapid growth, from 138 athletes from 17 countries that participated in Rome 1960, to more than 4,000 who took part in the 2012 Summer Paralympics (Bailey, 2008).

Over time, the Paralympic sports have had a progressive growth in sporting activities, which have directly led to the increase in the number of athletes, adding to the original principle of the sport a method of rehabilitation and inclusion, activities with large physical, emotional or mental demands, which places it at the level of conventional sports (Bailey, 2008).

And this growth brings many benefits in the life of an athlete on disability status, it is clear that they must take other unfavourable consequences added to their basic condition and triggered by different factors (high volume and intensity of training and competition, the use of prosthesis, underlying diseases, anatomical abnormalities, etc.) (Webborn and Emery, 2014). The sport can generate positive stimuli and multiple benefits for health and quality of life, but also may be associated with risk of injury (Fagher and Lexell, 2014). This can be an extra burden and constitute an important economic expenditure, taking into account medical treatment, rehabilitation and the impact on the work capacity (Willick et al., 2013). This added to the particular conditions of athletes with disabilities, has generated increased interest on the effects of sports in the Paralympic athlete (Patatoukas et al., 2011). However, to our knowledge, there is little research on the causes of injury from sports participation among disabled athletes (Willick et al., 2013). In addition, there are other difficulties in epidemiological studies in Paralympic Sports [6], among them are: (1) Lack of standardized definitions for reporting injuries and their details, (2) short-time tracking studies and (3) the use of self-report surveys that is not confirmed by medical diagnosis.

Different tools have being proposed in order to standardize data and epidemiological records of injuries in Paralympic sports, focusing mainly on the search of risk factors (Ferrara et al., 1992; Paterno et al., 2013) One of these measures was the injury surveillance system of the International Paralympic Committee, which was implemented from the Paralympic Winter Games 2002 (Willick et al., 2016, Willick et al., 2013). Also, the first summer games in which injury and illness surveys took place, were the 2012 Summer Paralympics and from there the first study that was published, reported incidence rates of specific injury of the sport considering exposure to risk (Derman et al., 2013; Willick et al., 2016, Willick et al., 2013; Manonelles et al., 2005).

The first 'Paranacionales' Games in Colombia took place in 2004, where 1,213 athletes from 28 regions of the country participated, and in the last one held in 2015, more than 2000 athletes from 31 regions participated. Notwithstanding, records of frequency and characteristics of injuries are rare in this population, in addition, what is reported in the literature, corresponds to data obtained at sporting events, regardless of information on behavioural injury during preparation for an fundamental competition (Agudelo and Seijas, 2012; Herman et al., 2015). The identification of sports injuries and the different factors that can influence the appearance, frequency and severity of these athletes in disability status, based on the definition of epidemiological data in the region is required. With this knowledge, it would be possible to promote intervention programs focused on preventing sports injuries of athletes with disabilities. For this reason, the aim of this study was to describe the injuries and related factors affecting Colombian athletes with physical and sensory-visual disabilities. 


\section{METHODS}

\section{Participants}

One hundred and sixty-five (165) clinical records of athletes with physical, visual and cerebral palsy disabilities (CP) members of the Bogota team that participated in the sports included and accepted by the International Paralympic Committee in the period between the years 2013 to 2015 and classified for the 2015 'Juegos Paranacionales', were chosen for this study. This research was conducted as part of the training program of athletes under the supervision of coaches and with the approval of the UCAD - (Spanish acronym for Applied Sports Science Unit) directors, a branch of the District Institute for Recreation and Sports responsible for conducting the corresponding biomedical control and registration of athletes for Paralympic program performance. This was completed following the ethics code of the Helsinki Declaration and with approval from the Institutional Committee of Ethics.

The medical records of athletes who met the following criteria were accepted into the study: (1) Athletes classified for the 2015 'Juegos Paranacionales', (2) diagnosed with sports injuries by medical personnel specialized in sports medicine and (3) management and monitoring their sports injury by the UCAD.

\section{Methodology}

The medical records of athletes who were part of the archive of the UCAD were reviewed and the necessary data from each one were taken to fill out the form. The whole process was carried out from July to October 2016.

The collected data variables on the form were:

- $\quad$ Sports age: Number of years from starting date in current sport to 01/11/2015.

- Disabilities (Timpka et al., 2014):

○ Physical:

- Raquimedular trauma (RMT);

- Amputees;

○ Visual.

- Les Autres.

○ CP.

- $\quad$ Sport: As per Table 1.

- Usage of disability-related items (non-sporting): Elements with related medical indication and disabled dependent (wheelchair, prosthesis or orthesis) (Timpka et al., 2014).

- Activity in which the injury occurs: Moment of sport practice (training or competition).

- Injury: Physical complaint or observable damage to the body caused by the experienced or sustained transfer of energy by an athlete during participation in training or competition, regardless of whether he received medical attention (yes or no) (Timpka et al., 2014).

- Type of injury: If the previous question was yes, it was classified according to Table 2.

- Place of injury: According to Table 3.

- Lost time: Time in which the athlete cannot be part of training or competition from the day following the incident (number of days).

- Severity: Number of days lost by the athlete from the day after injury started to the day the athlete fully returned to training and is available for competition (Timpka et al., 2014): 
- Minor: 1 to 7 days, which can be subdivided into mild (1 day), Low (2-3 days) or moderate (4 -7 days).

- Moderately severe: 8 to 28 days.

- Serious: $>28$ days to 6 months.

$\circ$ Long-term: $>6$ months.

- Starting mode: Characteristics of the onset of symptoms in time. It was divided into sudden onset (presentation of symptoms: severely, suddenly, and without warning) and gradual onset (appearance of symptoms not clear and with progressive increase) (Timpka et al., 2014).

- Anatomical structure: as Table 4.

- Causes: Triggering of injury was classified in (Timpka et al., 2014):

a. Traumatizing.

i. Contact.

1. With another athlete.

2. Moving object.

3. Stationary object.

ii. No contact.

b. Overuse injury.

Table 1. Classification of sports according to the Colombian Paralympic Committee (Timpka et al., 2014)

\begin{tabular}{lll}
\hline Physical & Visuals & Cerebral Palsy \\
\hline Chess & Chess & Boccia \\
Field athletics & Field athletics & Soccer 7 \\
Wheelchair Basketball & Tandem cycling & Swimming \\
Billiards & Soccer 5 & Table tennis \\
Cycling & Judo & Cycling \\
Weightlifting & Swimming & Athletics \\
Swimming & Sport shooting & Sialom \\
Field tennis in a wheelchair & Goalball & Equestrian \\
Table tennis & Bowling & Tennis field \\
Sport shooting & Field athletics & \\
Track athletics & & \\
\hline
\end{tabular}

Table 2. Classification of injuries according to Timpka et al., (2014)

\section{Name of the injury}

1. Concussion

2. Fracture (traumatic)

3. Stress fracture (overuse)

4. Other bone injuries

5. Luxation

6. Tendinous rupture

7. Ligament rupture

8. Sprain (joint or ligament injury)

9. Meniscus or cartilage injury

10. Muscular rupture

11. Bruising / hematoma / black \& blue
12. Tendinopathy

13. Arthritis / synovitis / bursitis

14. Fascia or aponeurosis injury

15. Impingement

16. Laceration, excoriation, skin injury

17. Dental injury or rupture

18. Nerve injury / spinal cord

19. Spasm or muscle contracture

20. Metaphysis / avulsions alteration

21. Other 
Table 3. Classification of part of the injured body according to Timpka et al. (2014)

\begin{tabular}{lll}
\hline Head and trunk & Upper extremity & Lower extremity \\
\hline 1. Face & 11. Shoulders / clavicle & 19. Hip \\
2. Head & 12. Arm & 20. Groin \\
3. Neck and cervical spine & 13. Elbow & 21. Thigh \\
4. Thoracic spine / back & 14. Forearm & 22. Knee \\
5. Sternum / ribs & 15. Wrist & 23. Leg \\
6. Lumbar spine / lumbar region & 16. Hand & 24. Achilles tendon \\
7. Abdomen & 17. Fingers & 25. Ankle \\
8. Pelvis / sacrum / gluteal region & 18. Thumb & 26. Foot \\
\hline
\end{tabular}

Table 4. Classification of anatomical structure according to Timpka et al. (2014)
1. Fascia
5. Articulation
2. Skin.
6. Bone
3. Subcutaneous tissue
7. Tendon
4. Muscle

\section{Statistical analysis}

The statistical analysis was carried out by using software SPSS $24.0 ®$ for Windows, Chicago. IL, USA. A descriptive analysis with measures of central tendency, frequencies and percentages was performed. Determining incidence was proportional, calculating the number of injuries of athletes for each sport.

\section{RESULTS}

The mean age of athletes was $32.3 \pm 12.04$ years and the mean sport age was $6.9 \pm 6.5$ years.

Table 5. Athletes' general characteristics $(n=165)$

\begin{tabular}{lcr}
\hline Variable & Number of athletes & $\%$ \\
\hline Gender & & \\
$\quad$ Male & 134 & 81.2 \\
$\quad$ Female & 31 & 18.8 \\
Laterality & & \\
Left & 22 & 13.3 \\
Right & 125 & 75.8 \\
Ambidextrous & 5 & 3 \\
Not identified & 13 & 57.9 \\
\hline
\end{tabular}

Tables 6 and 7 show the frequency in which athletes participated in each sport and the ratio of injuries per athlete respectively.

Table 6. Number of athletes per sport and type of disability

\begin{tabular}{|c|c|c|c|c|c|c|c|}
\hline \multirow[t]{2}{*}{ Sport } & \multicolumn{3}{|c|}{ Physical } & \multirow[t]{2}{*}{ Visual } & \multirow[t]{2}{*}{ CP } & \multirow[t]{2}{*}{ NR } & \multirow[t]{2}{*}{ Total } \\
\hline & RMT & Amputees & Les Autre & & & & \\
\hline Chess & & 1 & 1 & 2 & 1 & 1 & 6 \\
\hline Basketball & 4 & 3 & 2 & & 1 & & 10 \\
\hline Boccia & 1 & & 1 & & 6 & & 8 \\
\hline
\end{tabular}




\begin{tabular}{lcccccc}
\hline Cycling & 2 & 5 & 4 & 2 & 3 & 16 \\
Bowling & & & & 12 & & 12 \\
Soccer 5 & & & & 13 & & 13 \\
Soccer 7 & & & & & 8 & 8 \\
Judo & 2 & 3 & 3 & & 1 & 1 \\
Weightlifting & 6 & 7 & 5 & 5 & 2 & 9 \\
Swimming & & 14 & & & & 14 \\
Volleyball & 3 & 1 & 1 & & 1 & 6 \\
Field tennis & 4 & 1 & 5 & & 2 & 12 \\
Table tennis & 1 & & & & & 1 \\
Sport shooting & 2 & 1 & 3 & & 4 & 10 \\
Field athletics & 4 & 1 & & 7 & 2 & 14 \\
Track athletics & 29 & 37 & 25 & 42 & 31 & 1 \\
\hline Total & & & & & & 165 \\
\hline NR: Does not register & & & & & & \\
\hline
\end{tabular}

Of the 165 athletes, 99 had a total of 345 injuries to a prevalence of $60 \%$ and a proportional incidence of injuries of 2.09 per athlete in the period comprised between 2013 and 2015 (Table 7).

Table 7. Proportional incidence according to type of disability

\begin{tabular}{lccc}
\hline $\begin{array}{l}\text { Classification of athletes as per type of } \\
\text { disability }\end{array}$ & $\begin{array}{c}\text { Number of } \\
\text { athletes }\end{array}$ & $\begin{array}{c}\text { Amount of } \\
\text { injuries }\end{array}$ & $\begin{array}{c}\text { Rate of injuries per } \\
\text { athlete }\end{array}$ \\
\hline RMT & 29 & 59 & 2 \\
Amputees & 37 & 56 & 1.5 \\
Les Autres & 25 & 61 & 2.4 \\
CP & 31 & 80 & 2.6 \\
Visual & 42 & 89 & 2.1 \\
NR & 1 & & \\
\hline Total & 165 & 345 & 2.1 \\
\hline NR: Does not register & & & \\
\hline
\end{tabular}

Athletes on disability status using sports equipment are, for the most part, grouped in specific sports like basketball wheelchair (Table 8).

Table 8. Use of sports equipment

\begin{tabular}{ll}
\hline Type of implement & Number of athletes $(\%)$ \\
\hline Wheelchair & $34(20.6)$ \\
Orthesis or prosthesis & $14(8.5)$ \\
Do not use & $117(70.9)$ \\
\hline Total & $165(100)$ \\
\hline
\end{tabular}

The most frequent location area for injuries are the upper limbs (46\%), figure 1 shows in detail the areas involved.

The most injured anatomical structure was the muscles (31\%) (Figure 1). 


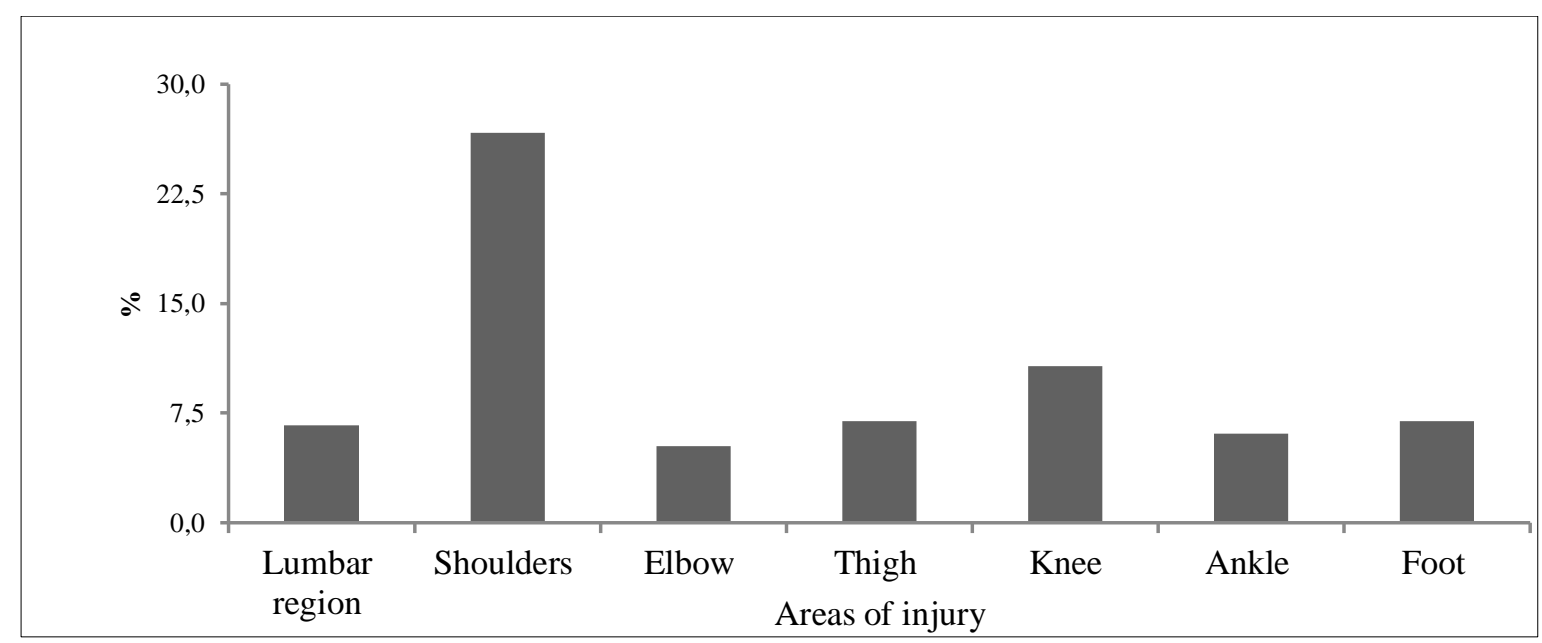

Figure 1. Areas of injury.

Among the sports with the greatest prevalence of injuries was athletics (24.6\%) the upper limbs area was the most common location, followed by cycling (18.8\%) and greater involvement of the lower limbs, and swimming (18\%) affecting mostly the upper limbs. Above $5 \%$ prevalence are sports like soccer $5(9.9 \%)$, soccer $7(6.1 \%)$ and table tennis (9\%).

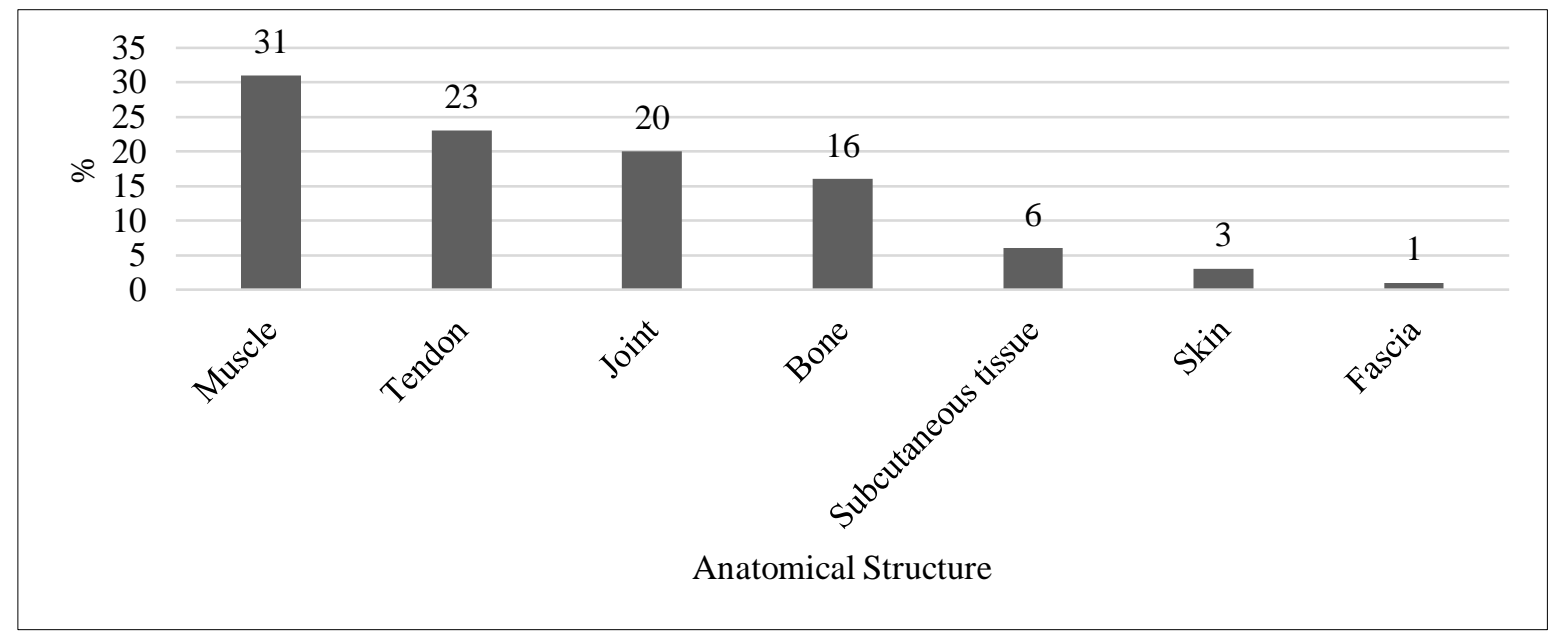

Figure 2. Injuries per anatomical structure.

Tables 9 and 10 summarized in detail sport injuries, area, and type of injury with its corresponding percentage.

$48 \%$ of the injuries were on the right side, $41 \%$ on the left side and $11 \%$ of injuries had bilateral occurrence.

Of 345 injuries, $90 \%$ occurred during training of athletes, being above the gradual appearance of injuries $(56.5 \%)$. The cause of the most common injuries was by the overuse mechanism (68.4\%), followed by trauma $(31.6 \%)$. Among these traumatic causes of injury, it was found that the most frequent were those generated by stationary objects (15.4\%) and non-contact (such sprains). 
Table 9. Amount of injuries according to sport and area of injury

\begin{tabular}{|c|c|c|c|c|}
\hline \multirow{2}{*}{ Sport } & \multicolumn{3}{|c|}{ Injury Area } & \multirow{2}{*}{ Total } \\
\hline & Head and Trunk & Upper Limbs & Lower Limbs & \\
\hline Chess & & 1 & & 1 \\
\hline Athletics & 20 & 40 & 25 & 85 \\
\hline Basketball & & 9 & 3 & 12 \\
\hline Boccia & & & 3 & 3 \\
\hline Cycling & 8 & 26 & 31 & 65 \\
\hline Bowling & 1 & 5 & & 6 \\
\hline Indoor football & 2 & 2 & 30 & 34 \\
\hline Soccer 7 & & 7 & 14 & 21 \\
\hline Judo & 1 & & & 1 \\
\hline Weightlifting & 4 & 9 & 1 & 14 \\
\hline Swimming & 13 & 37 & 14 & 64 \\
\hline Volleyball & & 2 & & 2 \\
\hline Tennis field & & 6 & & 6 \\
\hline Table tennis & 7 & 17 & 7 & 31 \\
\hline Total & 56 & 161 & 128 & 345 \\
\hline
\end{tabular}

Table 10. Amount and type of injury by sport

\begin{tabular}{|c|c|c|c|c|c|c|c|}
\hline Type of injury / Sport & Chess & Athletics & Basketball & Boccia & Cycling & Bowling & Indoor football \\
\hline Fracture & & & 1 & & 2 & & 2 \\
\hline Post stress fracture & & & & & & & 1 \\
\hline Other bone injuries & & 10 & 1 & 1 & 9 & & 6 \\
\hline Dislocations, & & & & & 2 & & 1 \\
\hline Tendinous rupture & & 1 & & & & & \\
\hline Sprain & & 5 & 1 & & 3 & & 5 \\
\hline Meniscus or cartilage dislocation & & 1 & & & & & 1 \\
\hline Muscular rupture & & 1 & & & & & 3 \\
\hline Contusion / bruise / purple & & 5 & 3 & 1 & 9 & 1 & 3 \\
\hline Tendinopathy & 1 & 19 & 4 & & 12 & 3 & \\
\hline Arthritis / synovitis / bursitis & & 4 & & & 2 & 1 & 3 \\
\hline Fascia injury or aponeurosis & & & & & 2 & 1 & 2 \\
\hline Impingement & & 1 & & & & & \\
\hline Laceration, abrasion, skin injury & & 4 & & & 7 & & 1 \\
\hline Spasm or muscle contracture & & 33 & 2 & & 13 & & 3 \\
\hline Other & & 1 & & 1 & 4 & & 3 \\
\hline Total & 1 & 85 & 12 & 3 & 65 & 6 & 34 \\
\hline Type of injury / Sport & Soccer 7 & Judo & Weightlifting & Swimming & Volleyball & Tennis field & Table tennis \\
\hline Fracture & 2 & & & & & & \\
\hline Other bone injuries & 3 & & 3 & 9 & & & 1 \\
\hline Sprain & 5 & & & 1 & & & 2 \\
\hline Meniscus or cartilage dislocation & 0 & & & & & & \\
\hline Muscular rupture & 1 & & & & & & \\
\hline Contusion / bruise / purple & 2 & 1 & & 2 & & & \\
\hline Tendinopathy & 3 & & 4 & 21 & 1 & 4 & 6 \\
\hline Arthritis / synovitis / bursitis & 1 & & 1 & 5 & & 1 & 5 \\
\hline $\begin{array}{l}\text { Fascia injury or aponeurosis } \\
\text { Impinqement }\end{array}$ & 1 & & & & 1 & & \\
\hline Spasm or muscle contracture & 2 & & 5 & 22 & & 1 & 15 \\
\hline Other & 1 & & 1 & 4 & & & 2 \\
\hline Total & 21 & 1 & 14 & 64 & 2 & 6 & 31 \\
\hline
\end{tabular}




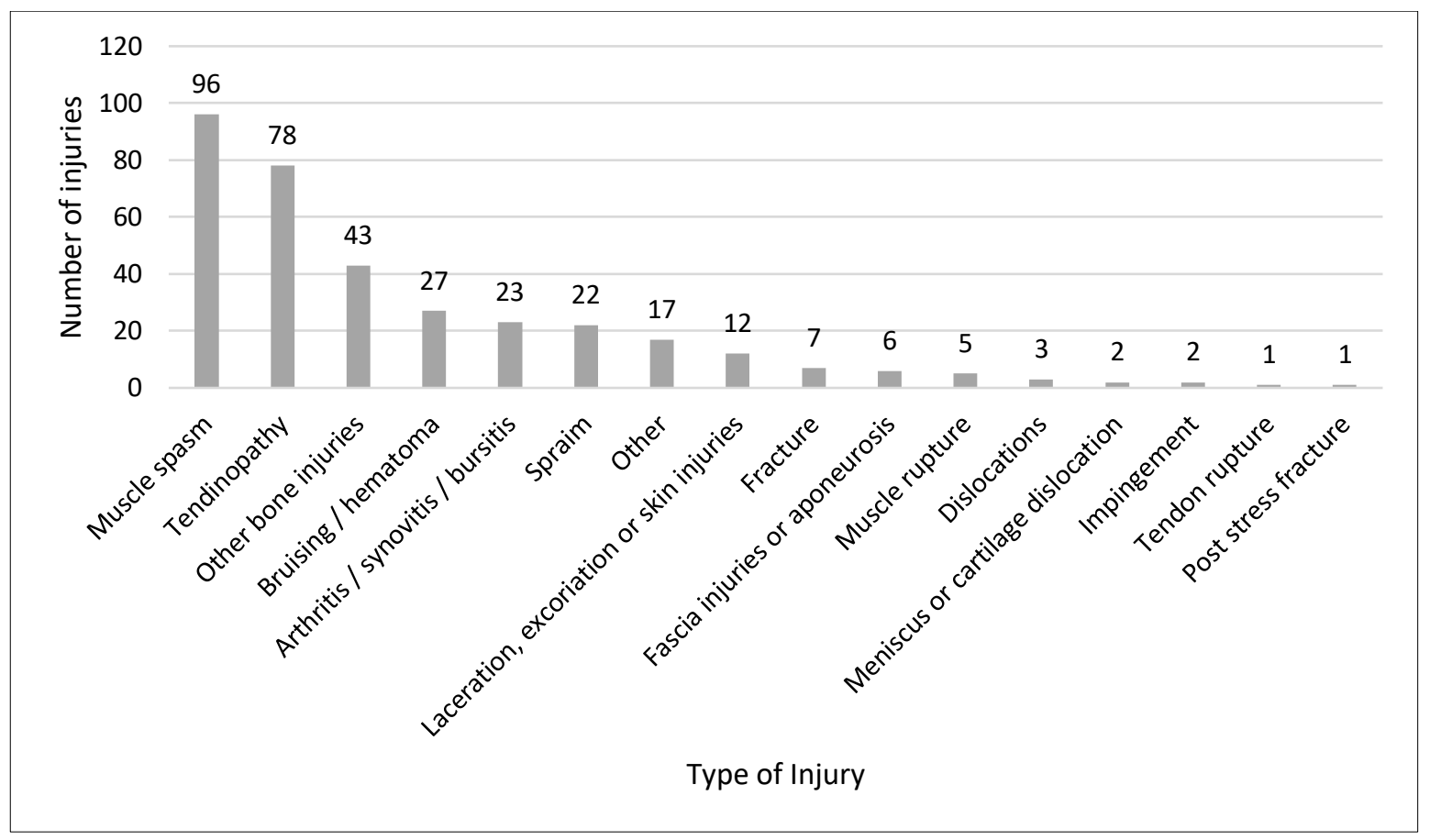

Figure 3. Number and type of injury.

\section{DISCUSSION}

Multiple studies have highlighted the importance of surveillance and monitoring of sports injuries in conventional athletes and disability status in order to know the epidemiology and aim intervention processes to improve overall performance and fitness of athletes (Curtis and Dillon, 1985; Engebretsen et al., 2013; Fagher and Lexell, 2014; Ferrara et al., 2000).

In recent years, there have been detailed and organized recommendations on the form and structure that most epidemiological studies should have, specifically detailing the behaviour of sports injuries (Curtis and Dillon, 1985; Levine et al., 2015 with the purpose of improving quality and strengthening scientific evidence, we based this research on those guidelines.

Many of the published studies of injuries in disability status athletes are performed in short periods of time and often describing the events of a specific competition (Curtis and Dillon, 1985; Ferrara et al., 1992; Ferrara et al., 2000). Our study, on the contrary, provides epidemiological description of injuries from a cohort composed of multiple sports, and all types of disabilities that make up the Paralympic movement for a period that integrates all the previous cycle to the national games held in 2015.

\section{Incidence and prevalence of injuries}

The prevalence of injuries found in the Bogotá team that participated in the National Games was $60 \%$ (99 injured / 165 athletes). This data varies from study to study; for example, Bernardi et al. (2003) showed a prevalence of $50.7 \%$ of muscle injuries in athletes with physical disabilities, Silva et al. (2013a; 2013b) showed $78 \%$ in track and field athletes visually impaired and $64 \%$ in swimming, Curtis and Dillon (1985) found a prevalence of injuries of $72 \%$ in athletes with physical disabilities. 
In various studies, in addition to the overall prevalence of injury information, the specific prevalence is reported by type of disability or sports. It should be clarified that the follow-up time of studies are very different and range from short observation periods (14 days) (Athanasopoulos et al., 2009), to monitoring for long periods but only during competitions (Ferrara et al., 2000;Silva et al., 2013a; 2013b) or as ours, for a continuous period including all stages of professional life, making comparison more difficult.

As for the description of general incidence, Manonelles et al. (2005) showed 1.47 injuries per athlete, a lower incidence than the present study, however only taking into account track and field athletes. Silva et al. (2013a; 2013b) found an incidence of 1.93 and 1.5 injuries per athlete, in visual athletes of athletics and swimming respectively. Curtis and Dillon (1985) reported an overall proportional incidence of 3.1 injuries per athlete, higher than this study, however he only includes 4 sports. The importance of this study highlights the fact that it is the only one revised to show an overall incidence in athletes of the Paralympic Movement including multiple sports.

Similar to what was found by Patatoukas et al. (2011), athletes with a lesser proportional incidence were amputee athletes, showing 0.97 injuries per athlete compared to 1.5 injuries per athlete on this study. Despite being the lowest incidence among different disability groups found by us, it is a high figure compared to the literature; this behaviour might be related to the extensive time of recording conducted in this study (2 years).

Several studies (Silva et al., 2013; Patatoukas et al., 2011; Curtis and Dillon, 1985; Athanasopoulos et al., 2009; Bernardi et al., 2003) the highest incidence and prevalence is in the athletes who use wheelchairs (athletics, basketball, table tennis, fencing, tennis etc.) contrary to this research that the highest incidence was in athletes with CP, without being low (2 injuries per athlete in a wheelchair). Clearly, data found in the literature on sports injuries in athletes with disability, vary depending on many factors such as, for example, type of research design used, availability of information such as exposure time or organization data by type of sports and disability. In this study, although it does not include athletes exposure time, it is important to calculate the incidence rate as Willick et al. (2013) and described as a factor to intervene (Fagher and Lexell, 2014), we conducted a proportional incidence according to type of disability, describing the number of injuries on each sport included, which can provide an inference on the reason of the results.

However, prospective studies on organized cohorts and structured monitoring should be designed with the purpose of recording injuries and all of its characteristics in addition to reliable information on demographics and inclusion of exposure times and inability to establish adequate monitoring, control and injury prevention.

\section{Demographic data of samples}

Given that Paralympic sport has evolved significantly, making its practitioners take a more professional role, the age range between these athletes is between 18 and 35 years with reports of major isolated ages 60 years (Fagher and Lexell, 2014). This resembles the results of this study, as the mean age is $32.3 \pm 12.04$ years. Older athletes are in sports like bowling and shooting classified $1 \mathrm{~A}$ (according to AHA), considering the strength and endurance component (Levine et al., 2016). In the Bogota team we found that mean sports age was 6.9 years, with a mode of 2 years and this figure is a better reflection of the population involved in most sports included.

It is important to highlight the low number of women in relation to men who were part of the study, which follows a similar pattern to previous studies (Webborn and Emery, 2014) and is not explained by greater overall proportion of disability status in the population (Agudelo and Seijas, 2012). Among causes we assume 
the explanation may be: lack of search, inclusion or little interest, either by the athletes or by sports institutions.

\section{Injury characteristics}

The injuries found in the Paralympic Bogota team, were mostly located in the upper limbs, specifically the shoulder, the same as Athanasopoulos et al. (2009), Bernardi et al. (2003), Willick et al. (2013) and Curtis and Dillion (1985). However, the result depends on the type of sport and disability as shown by Manonelles et al. (2005), the Silva et al (2013a; 2013b) and this study, where it is found that in sports like track and field athletes in the standing position, soccer 5 and 7 or athletes with CP and visual disabilities, injuries are more common in lower limbs. In turn, and related to most studies found, the anatomical structure and type of injury was most prevalent in muscle spasm or contracture being the most frequent diagnosis (Athanasopoulos et al., 2009; Bernardi et al., 2003; Curtis and Dillon, 1985; Lexell and Fagher, 2014; Ferrara et al., 2000). To facilitate recollection and data analysis on this study sports injuries were gathered in three groups: spasm or muscle contracture, muscular rupture and bruising. According to the Munich classification of (MuellerWohlfahrt et al., 2013) functional injuries that do not involve fibre rupture were included in injures type spasm or contracture, injury type $3 a, 3 b$ and 4 in muscle breakdown, and the type B in contusions. No type muscle laceration injuries occurred.

\section{Causal mechanism and start-up mode of injuries}

Overuse injuries in athletes from Bogota had a higher percentage compared to traumatic (68.4 vs. 31.6, respectively) similar to Silva et al. (2013a; 2013b) studies with evidence of $80 \%$ of injuries triggered by overuse mechanisms, and Webborn and Emery (2014) showed $58 \%$ of overuse injuries, contrary to Athanasopoulos et al. (2009) with a frequency $62.1 \%$ to $22.1 \%$ for traumatic injuries.

These variables are heavily influenced by the type of study according to the time of injury and characteristics of sport. In descriptive studies during competitive periods (e.g., Paralympics Games), the most common causal mechanism shall be traumatic ones and acute presentation, if it is for a long period of time, injuries shall be with overuse mechanisms and more gradual inception. In addition, if the study also specifies contact sports, injuries are of acute and traumatic presentation, but if it is endurance sports, injuries are usually overuse and gradual. (Herman et al., 2015; Webborn and Emery, 2014).

\section{Time of injury}

When we speak about the time of injury to determine whether the occurrence is in competing or during training, there is a direct dependence on the type of study, finding more publications for specific events, most often during the competitive period, for example Paralympics Games (Engebretsen et al., 2013; Willick et al., 2016.). The most common time for injuries of our study was injury during training $90 \%$, common datum in a sample for a long time, in which the proportion of time in competing compared to that of training is low. These results are similar to those found by Patatoukas et al. (2011) that is equal to this retrospective study and shows that $56.2 \%$ of the injuries occurred during training.

\section{CONCLUSIONS}

This is the first descriptive study of injury in athletes in condition of disability of the Paralympic Movement held in Bogota, Colombia. The general proportional incidence of injuries in athletes of the Bogota selected team in the time period comprised between 2013 and 2015 was 2.09 injuries per athlete and prevalence of injuries in athletes was $60 \%$. 
Most athletes who participated in these games were male and belonged to the group of physical disability.

The athletes with CP disabilities had the highest incidence of injury. Sports with the highest rate of injury were running, cycling and swimming. The area of most frequent injury are the upper limbs; however, it depends on the type of disability and according to the sport: athletes visually impaired and CP are injured more often at the lower limbs, contrary to athletes injured on wheelchair in which the upper limbs are compromised.

The most common type of injury was a muscle injury. It was not possible to define the type of injury according to time of evolution and severity due to lack of information in medical records. The moment where most injuries occur was identified in training, with gradual onset and the cause was overuse mechanism. It is important to conduct and encourage studies involving exposure time which is the clearest risk factor and associated with sports injuries.

Studies such as this are important because there is a (1) clear definition of variables and (2) extensive characterization of athletes and injuries, there is (3) an extended time for reviewing and (4) a large number of sports and sportsmen. On the other hand, being a retrospective study we have a low level of evidence and many possible biases. Lack of information in medical records negatively affects the accuracy of the findings, being in training there was no possibility to include athlete's exposure to the sport. It was not possible to determine time of disability and severity of the injury and no association to risk was found.

\section{ACKNOWLEDGMENTS}

We would like to thank all the participants in the study for their committed contribution. The authors would also like to thank the Faculty of Education and Sports Sciences at Institución Universitaria Escuela Nacional del Deporte (director José Fernando Arroyo Valencia and professor Sandra Parra) for their valuable support.

The experiments carried out in this study comply with the laws in force in the country in which they were made.

\section{REFERENCES}

Agudelo, L. H. L., \& Seijas, V. (2012). La discapacidad en Colombia: una mirada global. Revista Colombiana de Medicina Física y Rehabilitación, 22(2), 164-179.

Athanasopoulos, S., Mandalidis, D., Tsakoniti, A., Athanasopoulos, I., Strimpakos, N., Papadopoulos, E., ... \& Kapreli, E. (2009). The 2004 Paralympic Games: physiotherapy services in the Paralympic Village polyclinic. Open Sports Med J, 3(1), 1-8. https://doi.org/10.2174/1874387000903010001

Bailey, S. (2008). Athlete first: A history of the Paralympic movement. John Wiley \& Sons.

Bernardi, M., Castellano, V., Ferrara, M. S., Sbriccoli, P., Sera, F, \& Marchetti, M. (2003). Muscle pain in athletes with locomotor disability. Med Sci Sport Exer, 35(2), 199-206. https://doi.org/10.1249/01.mss.0000048635.83126.d4

Clarsen, B., Myklebust, G., \& Bahr, R. (2013). Development and validation of a new method for the registration of overuse injuries in sports injury epidemiology: the Oslo Sports Trauma Research Centre (OSTRC) overuse injury questionnaire. $\mathrm{Br} J$ Sports Med, 47(8), 495-502. https://doi.org/10.1136/bjsports-2012-091524

Curtis, K. A., \& Dillon, D. A. (1985). Survey of wheelchair athletic injuries: common patterns and prevention. Spinal Cord, 23(3), 170. https://doi.org/10.1038/sc.1985.29 
Derman, W., Schwellnus, M., Jordaan, E., Blauwet, C. A., Emery, C., Pit-Grosheide, P., ... \& Webborn, N. (2013). Illness and injury in athletes during the competition period at the London 2012 Paralympic Games: development and implementation of a web-based surveillance system (WEB-IISS) for team medical staff. Br J Sports Med, 47(7), 420-425. https://doi.org/10.1136/bjsports-2013-092375

Engebretsen, L., Soligard, T., Steffen, K., Alonso, J. M., Aubry, M., Budgett, R., ... \& Palmer-Green, D. (2013). Sports injuries and illnesses during the London Summer Olympic Games 2012. Br J Sports Med, 47(7), 407-414. https://doi.org/10.1136/bjsports-2013-092380

Fagher, K., \& Lexell, J. (2014). Sports-related injuries in athletes with disabilities. Scandinavian journal of medicine \& science in sports, 24(5), e320-e331. https://doi.org/10.1111/sms.12175

Ferrara, M. S., Buckley, W. E., McCann, B. C., Limbird, T. J., Powell, J. W., \& Robl, R. O. B. I. N. (1992). The injury experience of the competitive athlete with a disability: prevention implications. Medicine and science in sports and exercise, 24(2), 184-188. https://doi.org/10.1249/00005768-199202000$\underline{00005}$

Ferrara, M. S., Palutsis, G. R., Snouse, S., \& Davis, R. W. (2000). A longitudinal study of injuries to athletes with disabilities. Int J Sports Med, 21(03), 221-224. https://doi.org/10.1055/s-2000-300

Herman, D. C., Hess, J., Mistry, D. J., \& De Luigi, A. J. (2015). The para-athlete. DeLee and Drez's orthopaedic sports medicine principles and practice. 4th ed. Philadelphia: Elsevier, 356-64.

Junge, A., Engebretsen, L., Alonso, J. M., Renström, P., Mountjoy, M., Aubry, M., \& Dvorak, J. (2008). Injury surveillance in multi-sport events: the International Olympic Committee approach. Br J Sports Med, 42(6), 413-421. https://doi.org/10.1136/bjsm.2008.046631

Klenck, C., \& Gebke, K. (2007). Practical management: common medical problems in disabled athletes. Clin J Sport Med, 17(1), 55-60. https://doi.org/10.1097/jsm.0b013e3180302587

Levine, B. D., Baggish, A. L., Kovacs, R. J., Link, M. S., Maron, M. S., \& Mitchell, J. H. (2015). Eligibility and disqualification recommendations for competitive athletes with cardiovascular abnormalities: task force 1: classification of sports: dynamic, static, and impact: a scientific statement from the American Heart Association and American College of Cardiology. Journal of the American College of Cardiology, 66(21), 2350-2355. https://doi.org/10.1016/j.jacc.2015.09.033

Manonelles Marqueta, P., Arguisuelas Martinez, M., \& Santiago Fernandez, R. (2005). Number of injuries in high athletics competition of Paralympics sportsmen. Arch Med Deporte, 22(109), 371-9.

Mueller-Wohlfahrt, H. W., Haensel, L., Mithoefer, K., Ekstrand, J., English, B., McNally, S., ... \& Blottner, D. (2013). Terminology and classification of muscle injuries in sport: the Munich consensus statement. Br J Sports Med, 47(6), 342-350. https://doi.org/10.1136/bjsports-2012-091448

Patatoukas, D., Farmakides, A., Aggeli, V., Fotaki, S., Tsibidakis, H., Mavrogenis, A., ... \& Papagelopoulos, P. (2011). Disability-related injuries in athletes with disabilities. Folia medica, 53(1), 40-46. https://doi.org/10.2478/v10153-010-0026-x

Paterno, M. V., Taylor-Haas, J. A., Myer, G. D., \& Hewett, T. E. (2013). Prevention of overuse sports injuries in the young athlete. Orthop Clin N Am, 44(4), 553. https://doi.org/10.1016/j.ocl.2013.06.009

Silva, M. M. E., Bilzon, J., Duarte, E., Gorla, J., \& Vital, R. (2013). Sport injuries in elite paralympic swimmers with visual impairment. Journal of athletic training, 48(4), 493-498. https://doi.org/10.4085/1062-6050-48.4.07

Silva, M. M. E., Winckler, C., Silva, A. C. E., Bilzon, J., \& Duarte, E. (2013). Sports injuries in Paralympic track and field athletes with visual impairment. Med Sci Sports Exerc, 45(5), 908-913. https://doi.org/10.1249/mss.0b013e31827f06f3

Timpka, T., Alonso, J. M., Jacobsson, J., Junge, A., Branco, P., Clarsen, B., ... \& Renström, P. (2014). Injury and illness definitions and data collection procedures for use in epidemiological studies in Athletics (track and field): consensus statement. $\mathrm{Br} J$ Sports Med, 48(7), 483-490. https://doi.org/10.1136/bjsports-2013-093241 
Webborn, N., \& Emery, C. (2014). Descriptive epidemiology of Paralympic sports injuries. PM\&R, 6, S18S22. https://doi.org/10.1016/j.pmri.2014.06.003

Willick, S. E., Cushman, D. M., Blauwet, C. A., Emery, C., Webborn, N., Derman, W., ... \& Van de Vliet, P. (2016). The epidemiology of injuries in powerlifting at the London $2012 \mathrm{P}$ aralympic Games: An analysis of 1411 athlete-days. Scand J Med Sci Spor, 26(10), 1233-1238. https://doi.org/10.1111/sms.12554

Willick, S. E., Webborn, N., Emery, C., Blauwet, C. A., Pit-Grosheide, P., Stomphorst, J., ... \& Derman, W. (2013). The epidemiology of injuries at the London 2012 Paralympic Games. Br J Sports Med, 47(7), 426-432. https://doi.org/10.1136/bjsports-2013-092374

\section{(c) $(\mathrm{B})(\mathrm{E}$}

This work is licensed under a Attribution-NonCommercial-NoDerivatives 4.0 International (CC BY-NC-ND 4.0). 